\title{
Activity changes following sulcal, but not medial, ablation of the prefrontal cortex of the guinea pig
}

\author{
HANS J. MARKOWITSCH, WOLFGANG GULDIN, \\ JOSEF KESSLER, and RUDOLF RIESS \\ University of Konstanz, D-7750 Konstanz, Federal Republic of Germany
}

\begin{abstract}
Running activity of guinea pigs was compared before and after ablation of the cortical projection areas of the medial and lateral sectors of the thalamic mediodorsal nucleus (sulcal vs. medial prefrontal cortex). Only ablation of the sulcal prefrontal cortex was followed by a significant increase in running activity. This result corresponds to similar observations made in another rodent species, the rat, and also made in nonrodent species. Therefore, it is concluded that, with respect to basic or unlearned functions, interspecies parallels can be drawn for the cortical projection area of the medial portion of the mediodorsal nucleus. At the same time, it is, however, emphasized that the prefrontal cortex cannot be considered to be structurally and/or functionally homogeneous among species.
\end{abstract}

Since 1884, when Ferrier and Yeo reported that prefrontally lesioned monkeys can be characterized both "by general apathetic indifference" and by "purposeless unrest" (p. 532), many data pro and contra activity changes in prefrontally lesioned animals have appeared. Gross (1963) and Gross and Weiskrantz (1964) distinguished between hyperactivity and hyperreactivity: "Stimuli which increase locomotor activity of normal monkeys (such as light) increase it further after principalis lesions. Stimuli which depress locomotor activity of normal monkeys (such as novel sounds) depress it more after this lesion"' (Gross \& Weiskrantz, 1964, p. 86). This kind of relationship has been reported frequently, especially in the human and nonhuman primate literature (e.g., Bauer \& Fuster, 1978; Fulton, 1951; Kennard, Spencer, \& Fountain, 1941; Rylander, 1939); it seems to be associated most closely with areas 8,10 , and 11 (Gross \& Weiskrantz, 1964; Richter \& Hines, 1937).

Studies measuring activity changes in prefrontal cats revealed a contradictory pattern (Markowitsch, Pritzel, Kessler, Guldin, \& Freeman, 1980; Skinner \& Lindsley, 1973; Smith, 1942; Villablanca, Marcus, \& Olmstead, 1976; Warren, 1964; Warren, Coutant, \& Cornwell, 1969; Warren, Kolb, \& Nonneman, cited in Kolb, 1974; Warren, Warren, \& Akert, 1962, 1972). Warren (1964; Warren et al., 1972) interpreted the increased activity levels observed in cats with prefrontal lesions as a deficiency in the cat's reactability to novel stimuli, an interpretation that is also con-

\footnotetext{
We are grateful to Frances $M$. Wharton for improving the English of the manuscript and to Michuru Sugawa for help during the experiment. Address all correspondence to H. J. Markowitsch, Department of Psychology, University of Konstanz, P.O. Box 5560, D-7750 Konstanz, Federal Republic of Germany.
}

sistent with the observation of beneficial effects of a stimulus-poor environment on activity and learning tests in prefrontally lesioned monkeys (Bauer \& Fuster, 1978; Isaac \& DeVito, 1958; Malmo, 1942).

In line with this argument are results showing higher percentages of correct responses in learning tasks in prefrontally lesioned animals when these animals are tested under barbiturates (Wade, 1947; Weiskrantz, Gross, \& Baltzer, 1965) or when they participate in learning tasks, in which the animal's responses have been guided by particularly clear structuring of relevant task dimensions (Pohl, 1973; Pribram \& Tubbs, 1967; Wagman, 1968).

Results of activity measurements following frontal injury of the rat's cortex are more consistent than the corresponding results in cats (Beach, 1941; Kolb, 1974; Lynch, 1970; Richter \& Hawkes, 1939; Zubek \& DeLorenzo, 1952). Although an increase in general activity was noted in most studies following anterior cortical lesions, some of the earlier results have to be considered cautiously, as these authors were unaware of the cortical loci of afferent fibers from the mediodorsal nucleus (Leonard, 1969).

In a relatively recent study (Kolb, 1974), a clear distinction in activity changes has been reported following lesions of either the medial or the sulcal prefrontal cortex (nomenclature after Leonard, 1969); Rats with lesions of the cortical projection area of the lateral part of the mediodorsal nucleus (medial prefrontal cortex) manifested only mild increases in running-wheel activity, while rats with lesions of the cortical projection area of the medial part of the mediodorsal nucleus (sulcal prefrontal cortex) showed marked increases in activity levels.

As lesions in Kolb's study were based on the cortical target loci of the medial and lateral portions of the 
mediodorsal nucleus, a similar dissociation of activity changes could be expected in another rodent species, the guinea pig, if selective lesioning of its cortex on the basis of afferents from the lateral and medial parts of the mediodorsal nucleus is performed.

To prove this, we tested the running activity of guinea pigs both before and after a selective lesion of the cortical target area of either the medial or lateral portion of the mediodorsal nucleus (Markowitsch \& Pritzel, in press). Unlike Kolb (1974), we chose to test activity changes in a stationary box. First, this situation appears to depend less on possible irrelevant stimulation (Gross, 1968) than does the running wheel, and second, we had observed in preliminary experiments that guinea pigs perform, at the most, only one or two revolutions within $15 \mathrm{~min}$ in a running wheel.

\section{METHOD}

\begin{abstract}
Subjects
Twenty-five male, tricolored guinea pigs (Cavia porcellus), weighing between 550 and $660 \mathrm{~g}$, were employed. All animals were housed individually and maintained on a standard diet of commercial food, supplemented by ascorbic acid, carrots, and dandelions. Water was always available. The guinea pigs were assigned randomly to groups with ablation of the sulcal $(n=13)$ and medial $(n=12)$ prefrontal cortex.
\end{abstract}

\begin{abstract}
Apparatus
A square wooden arena (side length: $60 \mathrm{~cm}$, height: $20 \mathrm{~cm}$ ), covered totally with a detachable wooden top, was used for activity measurements. In some tests, the cover of the arena consisted of translucent Plexiglas and a lamp was positioned directly over the center of the arena.

Two pairs of beams were placed in the center of two adjoining sides of the arena $(6 \mathrm{~cm}$ above the base and $16 \mathrm{~cm}$ from the corner). Opposite to each beam, a photocell was positioned. Each interruption of any of the four beams was recorded over a 15-min period on a counter (Coulbourn Instruments) and on a cumulative recorder (Gerbrands Instruments) (cf. Gross, 1968). The luminance of the inside of the arena was $1.2 \mathrm{~cd} / \mathrm{m}^{2}$ when the arena was covered with a wooden top and $40 \mathrm{~cd} / \mathrm{m}^{2}$ when covered with the translucent top (both values are medians of values takens from five measuring points using a Tektronix J 16 Digital Photometer).
\end{abstract}

\section{Procedure}

Following three adaption sessions in the arena, recording of activity started by putting the guinea pigs into the arena with a wooden cover for $15 \mathrm{~min}$ at approximately the same hour each day. Recordings were performed every second day over two 16day periods, one preoperatively and one postoperatively. Animals received food only after testing. Following surgery, a break of 10 days was interposed between the testing sessions.

In order to elucidate whether or not the postoperative activity changes were dependent on the grade of illumination, additional activity measurements, using the translucent cover, were performed on three guinea pigs both pre- and postoperatively (one medial, two sulcal animals).

\section{Surgery}

Animals were anesthetized with Equithesin $(2.8 \mathrm{ml} / \mathrm{kg}$ ip). Using a Zeiss operation microscope, either the medial or the sulcal prefrontal cortex was removed by subpial aspiration with the aid of a fine sucker. The amount of cortex to be removed was determined on the basis of anatomical information obtained using the horseradish peroxidase technique (Markowitsch \& Pritzel, in press).

\section{Histology}

After the tests, the guinea pigs were deeply anesthetized under pentobarbital sodium and transcardially perfused with saline and $10 \%$ buffered Formalin in saline. Brains were then processed as described previously (Markowitsch \& Pritzel, 1977a). In brief, the lesion loci were photographed before storing the brains in $30 \%$ sucrose-Formalin until they sank. Thereafter, they were cut frozen at $60 \mu \mathrm{m}$. Every fifth section was mounted and stained with cresyl violet. Sections were magnified 9-17.5 times under an enlarger (Zeiss, Jena), and outlines of lesioned areas were copied onto paper. Loci of lesions were compared with standard drawings from the atlases of Luparello (1967) and of Rössner (1965). These two atlases were also used for determining the locus and extent of retrograde thalamic degeneration.

The extent of individual lesions was determined independently by two persons using millimeter paper. The degree of concordance was proved statistically.

\section{Statistics}

For all comparisons, nonparametric statistical tests were used. As a measure of the central tendency of a distribution, medians were computed. Significance values are given for two-tailed testing.

\section{RESULTS}

\section{Anatomy}

A highly significant correlation was found in the extents of the lesions as determined between the two raters (Spearman-rank correlation coefficient; $\mathrm{r}_{\mathrm{S}}=$ $+.79, \mathrm{n}=25, \mathrm{p}<.001)$. Figure 1 provides crosssectional examples of lesions of one guinea pig from each group.

Lesions of both the medial and sulcal prefrontal cortex were generally symmetrical and confined to the cortical target zone of the corresponding part of the mediodorsal nucleus. The frontal polar region, in which projections from medial and lateral parts of

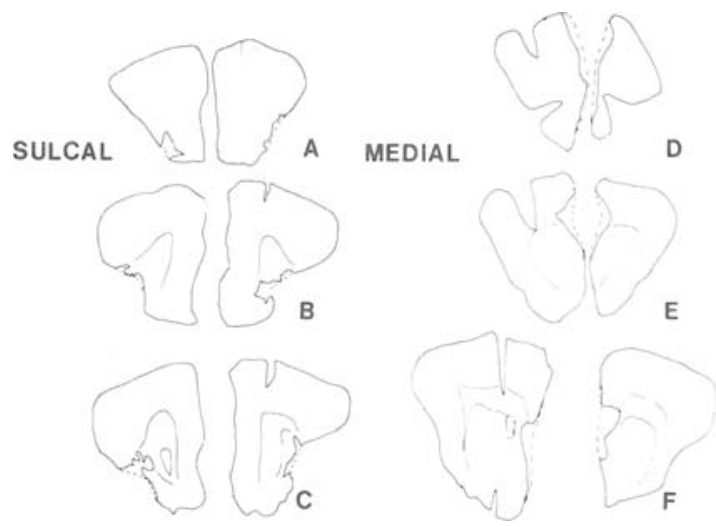

Figure 1. Drawings from mounted coronal sections from guinea pigs with sulcal (A-C) and medial (D-F) prefrontal lesions. In both animals, the extent of the lesion (dashed lines) is shown from anterior $(A, D)$ to posterior $(C, F)$ levels. 
the mediodorsal nucleus overlap (Markowitsch \& Pritzel, in press), was excluded from the lesioned area in all but one sulcal and four medial animals. In the latter five cases, minor lesions were detected.

In five of the 13 guinea pigs with lesions of the sulcal prefrontal cortex, underlying portions of the olfactory tract were partly severed.

In general, degenerative changes within the mediodorsal nucleus were found to be only slight. Subregions of observable degeneration corresponded to the subregions of the mediodorsal nucleus as established by the horseradish peroxidase technique.

\section{Behavior}

In Table 1 , the performance of the guinea pigs during the eight preoperative sessions is compared with that during the eight postoperative sessions. As can be seen from this table, only the sulcal group manifested marked increases in activity levels postoperatively. Although the changes in activity levels observed in the sulcal group were largest during the first three postoperative sessions (sulcal group: Wilcoxon $\mathrm{T}=12, \mathrm{n}=13, \mathrm{p}<.02$; medial group: $\mathrm{T}=55, \mathrm{n}=12, \mathrm{p}>.10$ ), changes in the number of breaks of photobeams before and after cortical ablations were still significant for this group when values were compared over the total, eight-session, preoperative periods (sulcal group: $T=16, n=13, p<$ .04 ; medial group: $\mathrm{T}=34, \mathrm{n}=12, \mathrm{p}>.10$; $\mathrm{cf}$. Figure 2).

Preoperative and postoperative performance levels under intense illumination were largely similar to those under dim light. That is, consistent activity changes were observed in both animals with sulcal lesions, while the guinea pig with a medial lesion did not manifest consistent activity changes after surgery.

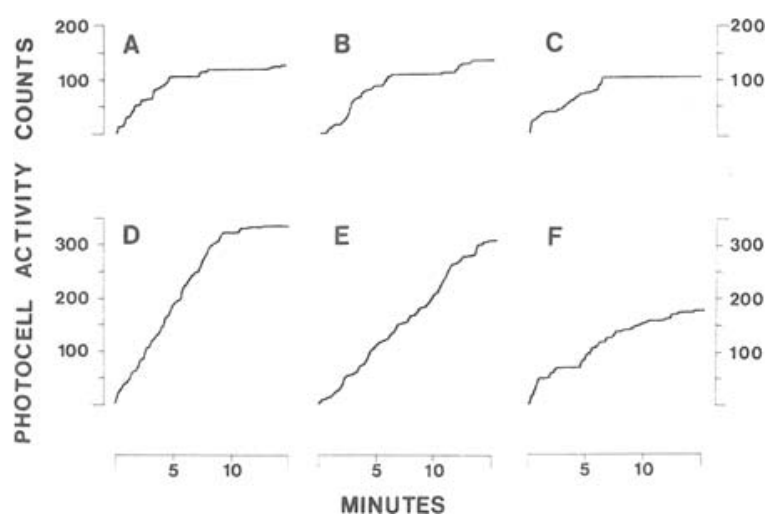

Figure 2. Cumulative records of testing sessions of one guinea pig with a sulcal prefrontal lesion. A, B, C: records of the last three preoperative testing days; D, E, F: records of the first three postoperative testing days.

\section{DISCUSSION}

The present investigation disclosed, with respect to changes in activity, a similar dissociability of prefrontal subfields of the guinea pigs as had been established in the rat (Kolb, 1974). This outcome appears significant, as the behavior of rats and guinea pigs had been found to differ considerably in various behavioral situations (e.g., Campbell, Misanin, White, \& Lytle, 1974; Glickman \& Hartz, 1964; Jonson, Lyle, Edwards, \& Penny, 1975; Pearl, 1963; Riess, 1934), despite the fact that both species are members of the rodent order.

It appears that the rather similar organization of the thalamocortical relationships of subregions of the mediodorsal nucleus of rat and guinea pig (cf. discussion in Markowitsch \& Pritzel, in press) is paral-

Table 1

Activity of the 25 Guinea Pigs Before and After Lesions of the Medial (12 Animals) and Sulcal Prefrontal (13 Animals) Cortex

\begin{tabular}{|c|c|c|c|c|c|c|c|}
\hline \multicolumn{4}{|c|}{ Lesions of Medial Cortex } & \multicolumn{4}{|c|}{ Lesions of Sulcal Prefrontal Cortex } \\
\hline \multirow[b]{2}{*}{ Animal } & \multicolumn{2}{|c|}{ Sum of Breaks } & \multirow[b]{2}{*}{ Difference* } & \multirow[b]{2}{*}{ Animal } & \multicolumn{2}{|c|}{ Sum of Breaks } & \multirow[b]{2}{*}{ Difference* } \\
\hline & Preoperative & Postoperative & & & Preoperative & Postoperative & \\
\hline M1 & 2,150 & 1,537 & -613 & S1 & 1,342 & 1,427 & 85 \\
\hline M2 & 2,062 & 2,107 & +45 & $\mathrm{~S} 2$ & 791 & 885 & +94 \\
\hline M3 & 304 & 728 & +424 & S3 & 1,511 & 1,880 & $+\quad 369$ \\
\hline M4 & 748 & 577 & -171 & S4 & 225 & 2,382 & $+2,157$ \\
\hline M5 & 3,000 & 2,415 & -585 & S5 & 1,800 & 3,993 & $+2,193$ \\
\hline M6 & 2,023 & 1,705 & -318 & S6 & 1,749 & 1,131 & $-\quad 618$ \\
\hline M7 & 2,352 & 3,179 & +827 & S7 & 1,516 & 4,865 & $+3,349$ \\
\hline M8 & 2,264 & 2,560 & +296 & S8 & 2,408 & 2,595 & $\begin{array}{r}187 \\
+\quad 187\end{array}$ \\
\hline M9 & 2,076 & 1,758 & -318 & S9 & 2,281 & 2,286 & 5 \\
\hline M10 & 1,450 & 1,776 & +326 & S10 & 2,095 & 1,179 & 916 \\
\hline M11 & 1,812 & 2,049 & +237 & S11 & 1,084 & 1,836 & 752 \\
\hline M12 & 1,191 & 1,698 & +507 & S12 & 1,858 & 2,232 & $+\quad 374$ \\
\hline & & & & S13 & 1,742 & 3,954 & $+2,212$ \\
\hline Sum & 21,432 & 22,089 & +657 & Sum & 20,402 & 30,645 & $+10,243$ \\
\hline Median & $2,042.5$ & 1,767 & +141 & Median & 1,742 & 2,232 & $+\quad 374$ \\
\hline
\end{tabular}

*Difference $=$ postoperative minus preoperative breaks. 
leled by-at least some-common functional properties. Evidence in favor of this hypothesis is derived not only from the present study, but also from a delayed-alternation paradigm (Markowitsch \& Riess, in press). In agreement with the findings of Kolb, Nonneman, and Singh (1974) and of Larsen and Divac (1978) in the rat, Markowitsch and Riess have shown that lesions of the medial, but not of the sulcal, prefrontal cortex of the guinea pig result in an impaired performance in a delayed-response-type task.

The qualitative similarity of the changes in activity levels following sulcal lesions together with some related observations in monkeys (Gross, 1968; Gross \& Weiskrantz, 1964) suggest that, with respect to basic or unlearned behaviors, parallels among mammalian species can be drawn for the cortical projection area of the medial portion of the thalamic mediodorsal nucleus.

It would be, however, not only premature and unproven, but also partially incorrect to conclude from these data that the structural and functional organization of the cortical projection area of the medial part of the mediodorsal nucleus is homogenous among all mammalian species. Counterevidence has been presented repeatedly both from an anatomical (e.g., Akert, 1964; Brodmann, 1912; Markowitsch \& Pritzel, 1979; Markowitsch, Pritzel, \& Petrović-Minić, 1980) and from a behavioral point of view (Markowitsch \& Pritzel, 1977b; Markowitsch, Pritzel, Kessler, et al., 1980).

Nevertheless, it is justified to conclude that the prefrontal cortex, when defined as the projection area of the thalamic mediodorsal nucleus, is a functionally heterogeneous structure in all species investigated so far.

\section{REFERENCES}

Akert, K. Comparative anatomy of frontal cortex and thalamofrontal connections. In J. M. Warren \& K. Akert (Eds.), The frontal granular cortex and behavior. New York: McGrawHill, 1964.

Bauer, R. H., \& Fuster, J. M. The effect of ambient illumination on delayed-response deficits from cooling dorsolateral prefrontal cortex. Behavioral Biology, 1978, 22, 60-66.

$\mathrm{BEACH}, \mathrm{F}$. A. Effects of brain lesions upon running activity in the male rat. Journal of Comparative Psychology, 1941, 31, 145-178.

Brodmann, K. Neue Ergebnisse über die vergleichende histologische Lokalisation der Grosshirnrinde mit besonderer Berüksichtigung des Stirnhirns. Anatomischer Anzeiger, 1912, 41, (Erganzungsheft), 157-216.

Campbell, B. A., Misanin, J. R., White, B. C., \& Lytle, L. D. Species differences in the ontogeny of memory: Indirect support for neural maturation as a determinant of forgetting. Journal of Comparative and Physiological Psychology, 1974, 87, 193-202.

Ferrier, D., \& Yeo, G. F. A record of experiments on the effects of lesion of different regions of the cerebral hemispheres. Philosophical Transactions of the Royal Society, 1884, 175, 479-565.
Fulton, J. F. Frontal lobotomy and affective behavior. A neurophysiological analysis. New York: Norton, 1951.

Glickman, S. E., \& HaRTZ, K. E. Exploratory behavior in several species of rodents. Journal of Comparative and Physiological Psychology, 1964, 58, 101-104.

Gross, C. G. Locomotor activity following lateral frontal lesions in rhesus monkeys. Journal of Comparative and Physiological Psychology, 1963, 56, 232-236.

Gross, C. G. General activity. In L. Weiskrantz (Ed.), Analysis of behavioral change. New York: Harper \& Row, 1968.

Gross, C. G., \& Weiskrantz, L. Some changes in behavior produced by lateral frontal lesions in the macaque. In J. M. Warren \& K. Akert (Eds.), The frontal granular cortex and behavior. New York: McGraw-Hill, 1964.

IsAac, W., \& DeVito, J. L. Effect of sensory stimulation on the activity of normal and prefrontal-lobectomized monkeys. Journal of Comparative and Physiological Psychology, 1958, 51, 172-179.

Jonson, K. M., Lyle, J. G., Edwards, M. J., \& Penny, R. H. C. Problems in behavioural research with the guinea pig: A selective review. Animal Behaviour, 1975, 23, 632-639.

Kennard, M. A., Spencer, S., \& Fountain, G., Jr. Hyperactivity in monkeys following lesions of the frontal lobes. Journal of Neurophysiology, 1941, 4, 512-524.

KoLB, B. Dissociation of the effects of lesions of the orbital or medial aspect of the prefrontal cortex of the rat with respect to activity. Behavioral Biology, 1974, 10, 329-343.

Kolb, B., Nonneman, A. J., \& Singh, R. K. Double dissociation of spatial impairments and perseveration following selective frontal lesions in rats. Journal of Comparative and Physiological Psychology, 1974, 87, 772-780.

Larsen, J. K., \& Divac, I. Selective ablations within the prefrontal cortex of the rat and performance of delayed alternation. Physiological Psychology, 1978, 6, 15-17.

LEONARD, C. M. The prefrontal cortex of the rat. I. Cortical projection of the mediodorsal nucleus. II. Efferent connections. Brain Research, 1969, 12, 321-343.

LUPARELLO, T. J. Stereotaxic atlas of the forebrain of the guinea pig. Basel: Karger, 1967.

LYNCH, G. S. Separable forebrain systems controlling different manifestations of spontaneous activity. Journal of Comparative and Physiological Psychology, 1970, 70, 48-59.

MaLmo, R. B. Interference factors in delayed response in monkeys after removal of frontal lobes. Journal of Neurophysiology, 1942, 5, 295-308.

Markowitsch, H. J., \& Pritzel, M. A stereotaxic atlas of the prefrontal cortex of the cat. Acta Neurobiologiae Experimentalis, 1977, 37, 63-81. (a)

Markowitsch, H. J., \& Pritzel, M. Comparative analysis of prefrontal learning functions in rats, cats, and monkeys. Psychological Bulletin, 1977, 84, 817-837. (b)

Markowitsch, H. J., \& Pritzel, M. The prefrontal cortex: Projection area of the thalamic mediodorsal nucleus? Physiological Psychology, 1979, 7, 1-6.

Markowitsch, H. J., \& Pritzel, M. The prefrontal cortex of the guinea pig (Cavia porcellus) defined as cortical projection area of the thalamic mediodorsal nucleus. Brain, Behavior and Evolution, in press.

Markowitsch, H. J., Pritzel, M., Kessler, J., Guldin, W., \& Freeman, R. B., JR. Delayed-alternation performance after selective lesions within the prefrontal cortex of the cat. Behavioural Brain Research, 1980, 1, 67-91.

Markowitsch, H. J., Pritzel, M., \& Petrović-Minić, B. Prefrontal cortex of the cat: Paucity of afferent projections from the parietal cortex. Experimental Brain Research, 1980, 39, 105-112.

Markowitsch, H. J., \& Riess, R. Delayed-alternation performance after selective lesioning of the medial and sulcal prefrontal cortex of the guinea pig. Brain, Behavior and Evolution, in press. 
PeArL, J. Avoidance learning in rodents: A comparative study. Psychological Reports, 1963, 12, 139-145.

PoHL, W. Dissociation of spatial discrimination deficits following frontal and parietal lesions in monkeys. Journal of Comparative and Physiological Psychology, 1973, 82, 227-239.

Pribram, K. H., \& Tubbs, W. E. Short-term memory, parsing and the primate prefrontal cortex. Science, 1967, 156, 1765 1767.

Richter, C. P., \& Hawkes, C. D. Increased spontaneous activity and food intake produced in rats by removal of the frontal poles of the brain. Journal of Neurology and Psychiatry, 1939, 2, 231-242.

Richte R, C. P.. \& Hines, M. Increased general activity produced by prefruntal and striatal lesions in monkeys. Transactions of the American Neurological Association, 1937, 63, 107-109.

RIESS, B. F. Limits of learning ability in the white rat and the guinea pig. Genetic Psychology Monographs, 1934, 15, 303-368.

RösSNE R, W. Stereotaktischer Hirnatlas vom Meerschweinchen. Lochham bei München: Pallas, ijú5.

Rylander, G. Personality changes after operations of the frontal lobes. A clinical study of 32 cases. Acta Psychiatrica et Neurologica, 1939, Suppl. 20, 1-327.

Skinner, J. E., \& Lindsley, D. B. The nonspecific mediothalamic-frontocortical system: Its influence on electrocortical activity and behavior. In K. H. Pribram \& A. R. Luria (Eds.), Psychophysiology of the frontal lobes. New York: Academic Press, 1973.

Smith, K. U. Hyperactivity in the cat after ablation of the frontal lobes and its relation to visually controlled aspects of behavior. Psychological Bulletin, 1942, 39, 493. (Abstract)

Villablanca, J. R., Marcus, R. J., \& Olmstead, C. E. Effects of caudate nuclei or frontal cortex ablations in cats. I.
Neurology and gross behavior. Experimental Neurology, 1976, 52, 389-420.

WADE, M. The effect of sedatives upon delayed response in monkeys following removal of the prefrontal lobes. Journal of Neurophysiology, 1947, 10, 57-61.

Wagman, A. M. I. The effect of frontal lobe lesions upon behavior requiring use of response-produced cues. Journal of Comparative and Physiological Psychology, 1968, 66, 69-76.

WARREN, J. M. The behavior of carnivores and primates with lesions in the prefrontal cortex. In J. M. Warren \& K. Akert (Eds.), The frontal granular cortex and behavior. New York: McGraw-Hill, 1964.

Warren, J. M., Coutant, L. W., \& Cornwell, P. R. Cortical lesions and response inhibition in cats. Neuropsychologia, 1969, 7, 245-257.

Warren, J. M., Warren, H. B., \& Akert, K. Orbitofrontal cortical lesions and learning in cats. Journal of Comparative Neurology, 1962, 118, 17-41.

Warren, J. M., Warren, H. B., \& Akert, K. The behavior of chronic cats with lesions in the frontal association cortex. Acta Neurobiologiae Experimentalis, 1972, 32, 361-392.

Weiskrantz, L., Gross, C. G., \& Baltzer, V. The beneficial effects of meprobamate on delayed response performance in the frontal monkey. Quarterly Journal of Experimental Psychology, 1965, 17, 118-124.

Zubek, J. P., \& DeLorenzo, A. J. The cerebral cortex and locomotor activity in rats. Canadian Journal of Psychology, $1952,6,55-70$.

(Received for publication February 6, 1980; revision accepted April 7, 1980.) 